\title{
The outcome of the first 100 nasopharyngeal cancer patients in Thailand treated by helical tomotherapy
}

\author{
Imjai Chitapanarux ${ }^{1,2}$, Wannapha Nobnop ${ }^{1,2}$, Patumrat Sripan ${ }^{1,2}$, Ausareeya Chumachote ${ }^{1}$ \\ Ekkasit Tharavichitkul'1,2, Somvilai Chakrabandhu1,2, Pitchayaponne Klunklin ${ }^{1,2}$, \\ Wimrak Onchan ${ }^{1,2}$, Bongkot Jia-Mahasap ${ }^{1,2}$, Suwapim Janlaor ${ }^{1}$, Patcharawadee Kayan ${ }^{1}$, \\ Patrinee Traisathit ${ }^{3}$, Dirk Van Gestel ${ }^{4}$ \\ ${ }^{1}$ Division of Radiation Oncology, Faculty of Medicine, Chiang Mai University, Chiang Mai, Thailand \\ ${ }^{2}$ Northern Thai Research Group of Radiation Oncology (NTRG-RO), Faculty of Medicine, Chiang Mai University, \\ Chiang Mai, Thailand \\ ${ }^{3}$ Department of Statistics, Faculty of Science, Chiang Mai University, Chiang Mai, Thailand \\ ${ }^{4}$ Department of Radiation Oncology, Institut Jules Bordet, Université libre de Bruxelles, Brussels, Belgium.
}

Radiol Oncol 2017; 51(3): 351-356.

Received 10 January 2017

Accepted 18 February 2017

Correspondence to: Imjai Chitapanarux, M.D., Division of Radiation Oncology, Faculty of Medicine, Chiang Mai University, Chiang Mai, Thailand, 110 Intawarorose Road, Chiang Mai, 50200, Thailand. E-mail: imjai@hotmail.com ; imjai.chitapanarux@cmu.ac.th

Disclosure: No potential conflicts of interest were disclosed.

Background. The aim of the study was to analyse of two-year loco-regional failure free survival (LRFFS), distant metastasis free survival (DMFS), overall survival (OS), and toxicity outcomes of the first 100 nasopharyngeal carcinoma patients in Thailand treated by helical tomotherapy.

Patients and methods. Between March 2012 and December 2015, 100 patients with non-metastatic nasopharyngeal carcinoma were treated by helical tomotherapy. All patients were treated by platinum-based concurrent chemoradiotherapy and adjuvant or neo-adjuvant chemotherapy.

Results. The median age was 51 years (interquartile ranges [IQR]: 42.5-57.0). The mean \pm SD of D95\% of planning target volume (PTV) 70, 59.4 and 54 were $70.2 \pm 0.5,59.8 \pm 0.6$, and $54.3 \pm 0.8 \mathrm{~Gy}$, respectively. The mean \pm SD of conformity index, and homogeneity index were $0.89 \pm 0.13$ and $0.06 \pm 0.07$. Mean \pm SD of D2 \% of spinal cord and brainstem were $34.1 \pm 4.4$ and $53.3 \pm 6.3 \mathrm{~Gy}$. Mean \pm SD of D50 of contralateral and ipsilateral parotid gland were $28.4 \pm 6.7$ and $38.5 \pm 11.2 \mathrm{~Gy}$. At a median follow-up of 33 months (IQR: 25-41), the 2-year LRFFS, DMFS, OS were 94\% (95\%Cl: 87-98\%), 96\% (95\% Cl: 89-98\%), and 99\% (95\% Cl: 93-100\%), respectively. Acute grade 3 dermatitis, pharyngoesophagitis, and mucositis occurred in 5\%,51\%, and $37 \%$, respectively. Late pharyngoesophagitis grade 0 and 1 were found in $98 \%$ and $2 \%$ of patients. Late xerostomia grade 0,1 and 2 were found in $17 \%, 78 \%$ and $5 \%$, respectively.

Conclusions. Helical tomotherapy offers good dosimetric performance and achieves excellent treatment outcome in nasopharyngeal carcinoma patients.

Key words: nasopharynx; cancer; helical tomotherapy

\section{Introduction}

Helical tomotherapy is an intensity-modulated radiotherapy (IMRT) dedicated system with an integrated megavoltage computed tomography (MVCT) scanner for patient position verification. The helical IMRT is able to produce highly confor- mal dose distribution to large and complex target volumes such as in nasopharyngeal carcinoma and other head and neck cancers. Helical tomotherapy can lower the mean dose to the salivary glands, with improved dose homogeneity and conformity compared to other IMRT techniques. ${ }^{1-5}$ In our centre, step and shoot IMRT was the standard radiother- 
apy technique in most nasopharyngeal carcinoma patients with curative intent treated since 2000. The helical tomotherapy unit, Hi-ART II (TomoTherapy Inc., Madison, WI) has been installed in March 2012. The aim of this study was to assess the treatment outcome in terms of loco-regional failure free survival (LRFFS), distant metastasis free survival (DMFS), overall survival (OS), and treatment toxicities of the first 100 non-metastatic nasopharyngeal carcinoma patients treated by this technique. Dosimetric details were also reported.

\section{Patients and methods}

We reviewed the first 100 patients with newly-diagnosed non-metastatic nasopharyngeal carcinoma patients treated with curative intent by helical tomotherapy between April 2012 and December 2015. Pretreatment evaluations consisted of physical examination, pre-treatment dental evaluations, and laboratory studies. Good bone marrow, renal, and liver function tests were required. Contrast enhanced computer tomography (CT) scan or magnetic resonance imaging (MRI) of the nasopharynx and the neck region, chest x-ray, and bone scan were performed. The diseases were staged according to the American Joint Committee on Cancer Staging 2010, $7^{\text {th }}$ edition. ${ }^{6}$

Target delineation was done according to RTOG 0225.7 The gross target volume (GTV) included the primary tumour and nodes larger than $1 \mathrm{~cm}$ in diameter or nodes with necrotic centres. Clinical target volume 70 (CTV 70) was equivalent to the GTV plus $5 \mathrm{~mm}$ margin. CTV 59.4 was defined as CTV 70 plus entire nasopharynx with retropharyngeal lymph nodes, pterygoid fossa, parapharyngeal space, inferior sphenoid sinus, posterior third of the nasal cavity and maxillary sinuses, skull base, and high risk nodal groups (upper deep jugular, subdigastric, midjugular, posterior cervical, and retropharyngeal lymph nodes). CTV 54 included the lower jugular and supraclavicular lymph nodes. Planning target volume (PTV) was created by adding a circumferential margin of $5 \mathrm{~mm}$ to each CTV. We also contoured the critical organs at risk such as bilateral parotid glands, brainstem, spinal cord, optic nerves and chiasm. For planning, the helical tomotherapy Planning Station (Hi-Art Version 4.2.3.9 TomoTherapy Inc., Madison, WI) was used with a Field Width (FW) of $5.02 \mathrm{~cm}$, a Pitch Factor (PF) of 0.287, and a Modulation Factor (MF) of 3.0. ICRU83 recommendations were implemented for the optimization procedure. The dose prescriptions in our simultaneous integrated boost technique (SIB) were 70 Gy for PTV 70 at 2.12 Gy/fraction, 59.4 Gy for PTV 59.4 at 1.8 Gy/fraction, and 54 Gy for PTV 54 at $1.64 \mathrm{~Gy} /$ fraction. Treatment was delivered in five fractions per week for a total of 33 fractions.

Acute adverse events of concurrent chemoradiotherapy were evaluated at weekly visits using version 3.0 of the National Cancer Institute Common Terminology Criteria for Adverse Events (NCI-CTCAE). ${ }^{8}$ Patients were evaluated for disease control, survival, and late toxicities of radiotherapy at 2-3 month intervals for the first 2 years, at 3-6 month intervals between the third and fifth year. Late toxicities were assessed by the RTOG/EORTC late radiation morbidity scoring system. ${ }^{9}$ At every visit fiber-optic endoscopy by an otolaryngologists has been done. CT scan of the neck was performed every 6 months in the first 2 years and annually thereafter.

OS and LRFFS were estimated using the KaplanMeier method. OS was defined as the time from beginning of treatment to the date of death of any cause. LRFFS was defined as the time between beginning of treatment and local or regional recurrence/progression, or death due to nasopharyngeal cancer or due to unknown causes with undocumented site of failure. DMFS was defined from beginning of treatment to the date of diagnosis of distant metastases. $P$-values $<0.05$ were considered statistically significant, and all $P$ values reported in this article are two-sided values, determined using Stata version 11 (StataCorp LP, College Station, TX, USA).

The results presented herein resulted from a retrospective study based on the analysis of medical records. This study was approved by the Ethics committee of Faculty of Medicine, Chiang Mai University.

\section{Results}

A hundred non-metastatic nasopharyngeal carcinoma patients have been treated with curative intent by helical tomotherapy. Baseline characteristics are shown in Table 1. The median age was 51 years (interquartile ranges [IQR]: 42.5-57.0). Most patients $(66 \%)$ had undifferentiated non-keratinizing nasopharyngeal carcinoma.

Treatment protocols for nasopharyngeal carcinoma in our centre include concurrent chemoradiotherapy plus either 3 cycles of induction chemotherapy (IC) or 3 cycles of adjuvant chemotherapy (AC). Of the 100 patients, all of them received 
TABLE 1. Patient and treatment characteristics

\begin{tabular}{lc}
\hline & \\
Characteristics & Values \\
& $\mathrm{N}=100$ \\
$\mathbf{N}(\%)$ \\
\hline Gender & \\
Female & $38(38 \%)$ \\
Male & $62(62 \%)$ \\
Histological subtype & \\
Keratinizing & $2(2 \%)$ \\
Non-keratinizing; differentiated & $32(32 \%)$ \\
Non-keratinizing; undifferentiated & $66(66 \%)$ \\
Stage & \\
II & $23(23 \%)$ \\
III & $45(45 \%)$ \\
IVA & $21(21 \%)$ \\
IVB & $11(11 \%)$ \\
T stage & \\
T1 & $28(28 \%)$ \\
T2 & $30(30 \%)$ \\
T3 & $20(20 \%)$ \\
T4 & $22(22 \%)$ \\
N stage & \\
N0 & $5(5 \%)$ \\
N1 & $30(30 \%)$ \\
N2 & $54(54 \%)$ \\
N3a & $7(7 \%)$ \\
N3b & $4(4 \%)$ \\
Dose statistic & \\
D95\% of PTV70, mean (SD) & \\
D95\% of PTV59.4, mean (SD) & $70.2(0.5)$ \\
D95\% of PTV54, mean (SD) & $59.8(0.6)$ \\
Conformity index (Cl), mean (SD) & $54.3(0.8)$ \\
Homogeneity index (HI), mean (SD) & $0.89(0.13)$ \\
D2\% of spinal cord, median (SD) & $0.06(0.07)$ \\
D2 cc of brainstem, mean (SD) & $34.1(4.4)$ \\
D50 of ipsilateral parotid gland, mean (SD) & $53.3(6.3)$ \\
D50 of contralateral parotid gland, mean (SD) & $38.5(11.2)$ \\
& $28.4(6.7)$ \\
\hline & \\
\hline & \\
&
\end{tabular}

platinum-based concurrent chemoradiotherapy, either weekly cisplatin $40 \mathrm{mg} / \mathrm{m}^{2} \times 6$ cycles $(53 \%)$, cisplatin $70 \mathrm{mg} / \mathrm{m}^{2}$ every 21 days $\times 3$ cycles $(11 \%)$, or weekly carboplatin $100 \mathrm{mg} / \mathrm{m}^{2} \times 6$ cycles $(36 \%)$. Forty-one patients ( $41 \%$ ) received 3 cycles of IC, because of N2 and N3a disease in 29\% and because of a waiting time for radiotherapy of more than 6 weeks in $15 \%$ of patients. Thirty patients $(30 \%)$ received IC with PF regimen (cisplatin $100 \mathrm{mg} /$ $\mathrm{m}^{2}$ on day 1 or carboplatin with area under curve (AUC) 5 on day 1 plus $5-F U ~ 1000 \mathrm{mg} / \mathrm{m}^{2} / \mathrm{d}$ in day 1-4 every 21 days). Eleven patients (11\%) received IC with TPF regimen (cisplatin $75 \mathrm{mg} / \mathrm{m}^{2}$ on day 1, docetaxel $75 \mathrm{mg} / \mathrm{m}^{2}$ on day $1,5-\mathrm{FU} 750 \mathrm{mg} / \mathrm{m}^{2} / \mathrm{d}$ in day 1-4 every 21 days). We performed CT scan after 3 cycles of IC for response evaluation and planning radiotherapy. Fifty-nine patients (59\%) received $\mathrm{AC}$ with $\mathrm{PF}$ regimen (cisplatin $100 \mathrm{mg}$ / $\mathrm{m} 2$ on day 1 plus 5 -FU $1000 \mathrm{mg} / \mathrm{m} 2 / \mathrm{d}$ in day $1-4$ every 21 days in 23 patients and carboplatin with area under curve (AUC) 5 on day 1 plus 5-FU 1000 $\mathrm{mg} / \mathrm{m}^{2} / \mathrm{d}$ in day $1-4$ every 21 days in 36 patients).

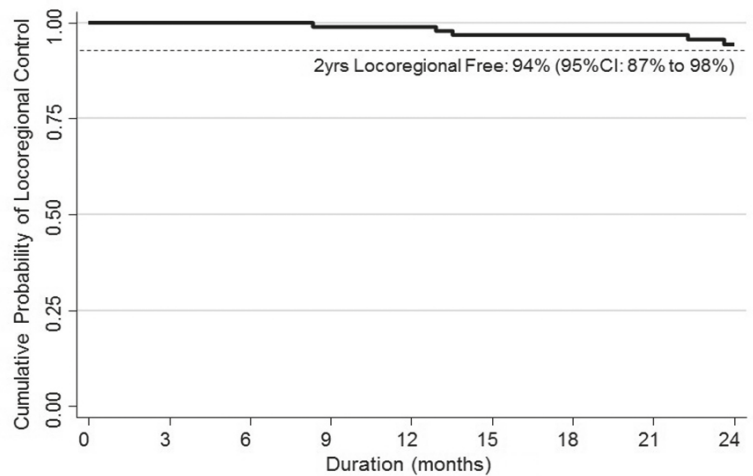

FIGURE 1. Kaplan-Meier estimate of loco-regional failure free survival (LRFFS).

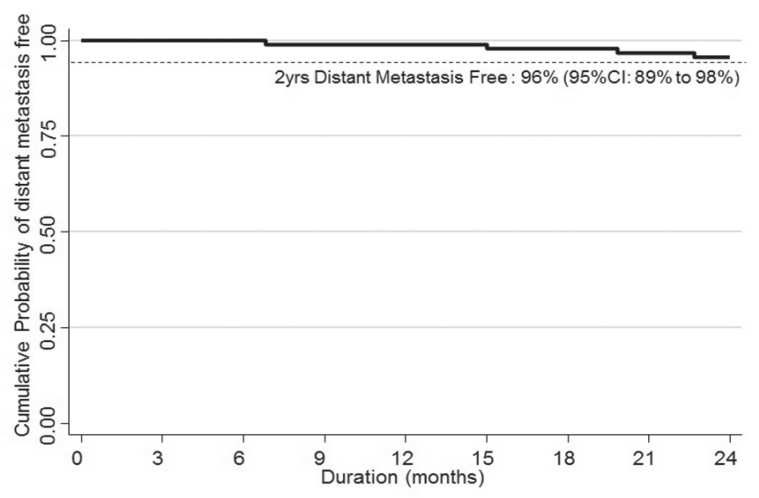

FIGURE 2. Kaplan-Meier estimate of distant metastasis free survival (DMFS).

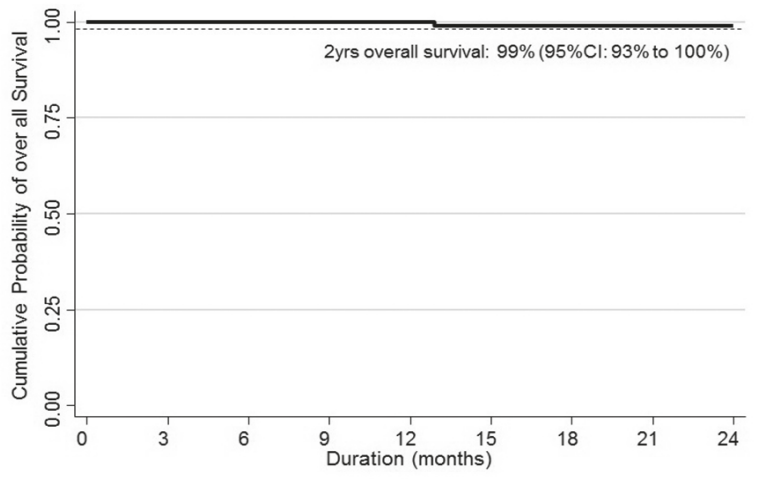

FIGURE 3. Kaplan-Meier estimate of overall survival (OS).

With a median follow up time of 33 months (inter-quartile range, IQR: 25-41 months), the 2-year LRFFS, DMFS and OS rates were $94 \%, 96 \%$, and 99\% respectively (Figures $1-3$ ). Ninety-nine patients were alive at the last follow up of whom 84 patients without any evidence of disease. No patients developed second primary cancer. 
TABLE 2. Comparative studies of outcome and toxicities in NPC treated by HT concurrent with chemotherapy

\begin{tabular}{|c|c|c|c|c|c|c|c|c|c|c|}
\hline \multirow[b]{2}{*}{ Study } & \multirow{2}{*}{$\begin{array}{l}\text { Median } \\
\text { Follow up } \\
\text { (Range) } \\
\text { (month) }\end{array}$} & \multirow[b]{2}{*}{$\begin{array}{l}\text { No. } \\
\text { of CCRT } \\
(\%)\end{array}$} & \multirow[b]{2}{*}{$\begin{array}{l}\text { LRFFS } \\
(\%)\end{array}$} & \multirow[b]{2}{*}{$\begin{array}{l}\text { DMFS } \\
(\%)\end{array}$} & \multirow[b]{2}{*}{$\begin{array}{l}\text { OS } \\
(\%)\end{array}$} & \multicolumn{5}{|c|}{ Severe toxicity (grade $>2$ ) } \\
\hline & & & & & & $\begin{array}{c}\text { Acute } \\
\text { Dermatitis } \\
(\%)\end{array}$ & $\begin{array}{l}\text { Acute } \\
\text { Mucositis } \\
(\%)\end{array}$ & $\begin{array}{c}\text { Acute } \\
\text { Pharyngitis } \\
(\%)\end{array}$ & $\begin{array}{c}\text { Acute } \\
\text { Xerostomia } \\
(\%)\end{array}$ & $\begin{array}{c}\text { Late } \\
\text { Xerostomia } \\
(\%)\end{array}$ \\
\hline Wong et al. 22 & $34(9-50)$ & 70 & $\begin{array}{l}93.6 \\
(3 \mathrm{yr})\end{array}$ & $\begin{array}{c}86.6 \\
(3 \mathrm{yr})\end{array}$ & $\begin{array}{c}87.2 \\
(3 \mathrm{yr})\end{array}$ & - & 67.4 & - & - & 2.3 \\
\hline $\begin{array}{l}\text { Wolden et } \\
\text { al. } 23\end{array}$ & $35(3-74)$ & 93 & $\begin{array}{c}91 \\
(3 \mathrm{yr})\end{array}$ & $\begin{array}{c}78 \\
(3 y r)\end{array}$ & - & - & - & - & - & - \\
\hline Kam et al. 24 & $29(8-45)$ & 30 & $\begin{array}{c}92 \\
(3 \mathrm{yr})\end{array}$ & $\begin{array}{c}79 \\
(3 \mathrm{yr})\end{array}$ & $\begin{array}{c}90 \\
(3 \mathrm{yr})\end{array}$ & - & 92 & - & 75 & $23(2 y r)$ \\
\hline Lee et al. 7 & $31(6-55)$ & 65 & $\begin{array}{l}89.3 \\
(2 \mathrm{yr})\end{array}$ & $\begin{array}{l}84.7 \\
(2 y r)\end{array}$ & $\begin{array}{l}80.2 \\
(2 \mathrm{yr})\end{array}$ & - & $\begin{array}{c}4.4 \\
\text { (grade4) }\end{array}$ & - & - & 3.1 \\
\hline Tham et al. 25 & 36.5 & 100 & $\begin{array}{l}93.1 \\
(3 \mathrm{yr})\end{array}$ & - & - & - & 29 & - & 3 & - \\
\hline Lee et al. 26 & $31(7-22)$ & 75 & $\begin{array}{c}98 \\
(4 \mathrm{yr})\end{array}$ & $\begin{array}{c}66 \\
(4 \mathrm{yr})\end{array}$ & $\begin{array}{c}88 \\
(4 \mathrm{yr})\end{array}$ & - & 94 & - & - & $2.5(2 \mathrm{yr})$ \\
\hline Liv et al. 27 & $13(8 / 18)$ & 58 & $\begin{array}{c}100 \\
(13 \mathrm{M})\end{array}$ & - & - & 5 & 79 & - & 5 & - \\
\hline Wang et al. 28 & $47.1(11-68)$ & 83 & $\begin{array}{c}94 \\
(4 \mathrm{yr})\end{array}$ & $\begin{array}{c}85 \\
(4 \mathrm{yr})\end{array}$ & $\begin{array}{l}86.1 \\
(4 \mathrm{yr})\end{array}$ & - & 33.3 & - & 4.7 & $12.3(2 \mathrm{yr})$ \\
\hline $\begin{array}{l}\text { Sultanem et } \\
\text { al. } 27\end{array}$ & $21.8(5-49)$ & 91 & $\begin{array}{c}100 \\
(4 \mathrm{yr})\end{array}$ & $\begin{array}{l}57 \\
(4 \mathrm{yr})\end{array}$ & $\begin{array}{c}94 \\
(4 \mathrm{yr})\end{array}$ & - & $\begin{array}{c}51 \\
\text { (grade3) }\end{array}$ & - & - & - \\
\hline Du et al. 20 & $32(3-38)$ & 64 & $\begin{array}{l}96.1 \\
(3 \mathrm{yr})\end{array}$ & $\begin{array}{c}92 \\
(3 \mathrm{yr})\end{array}$ & $\begin{array}{l}86.3 \\
(3 \mathrm{yr})\end{array}$ & 4.7 & 3.2 & - & 0 & - \\
\hline Leung et al. 17 & $41(0.2-67)$ & 62.5 & $\begin{array}{c}97 \\
(5 \mathrm{yr})\end{array}$ & $\begin{array}{l}84.6 \\
(5 y r)\end{array}$ & - & 0 & 4 & - & - & 0 \\
\hline Du et al. 21 & 23.7 (12-38) & 100 & $\begin{array}{l}92.2 \\
(2 \mathrm{yr})\end{array}$ & $\begin{array}{l}92.7 \\
(2 \mathrm{yr})\end{array}$ & $\begin{array}{l}93.2 \\
(2 \mathrm{yr})\end{array}$ & 5.3 & 9.1 & $\begin{array}{c}0.5 \\
\text { (grade 3) }\end{array}$ & 0 & - \\
\hline $\begin{array}{l}\text { Zhang et al. } \\
30\end{array}$ & 48 (41.7-58) & $\begin{array}{c}100 \\
\text { (cetuximab) }\end{array}$ & $\begin{array}{l}95.2 \\
(2 \mathrm{yr})\end{array}$ & $\begin{array}{l}88.1 \\
(2 \mathrm{yr})\end{array}$ & $\begin{array}{c}93 \\
(2 \mathrm{yr})\end{array}$ & $\begin{array}{c}7 \\
\text { (grade3) }\end{array}$ & $\begin{array}{c}81.4 \\
\text { (grade3) }\end{array}$ & - & - & - \\
\hline Our Study & $33(25-41)$ & 100 & $\begin{array}{c}94 \\
(2 \mathrm{yr})\end{array}$ & $\begin{array}{c}96 \\
(2 \mathrm{yr})\end{array}$ & $\begin{array}{c}99 \\
(2 \mathrm{yr})\end{array}$ & 5 & $\begin{array}{c}37 \\
\text { (grade3) }\end{array}$ & $\begin{array}{c}51 \\
\text { (grade 3) }\end{array}$ & - & $\begin{array}{c}5 \\
\text { (grade 3) }\end{array}$ \\
\hline
\end{tabular}

CCRT = concurrent chemoradiotherapy; DMFS = distant metastasis free survival; LRFFS = locoregional failure free survival; $M=$ month; $0 S=$ overall survival; $Y r=$ year

Acute and late toxicities of our study are shown in the bottom of Table 2 . Acute grade 3 Pharyngoesophagitis and mucositis occurred in $51 \%$ and $37 \%$ respectively, responsible for a weight loss of more than $15 \%$ from baseline in 42 patients $(42 \%)$ and with a nasogastric (NG) tube insertion in 10 patients $(10 \%$, in all during concurrent chemoradiotherapy). Five patients $(5 \%)$ had grade 3 acute radiation dermatitis. No patient died during concurrent chemoradiotherapy. Late pharyngoesophagitis was of grade 1 and was registered in only $2 \%$ of the patients. We also found grade 1 , 2 and 3 late xerostomia in $17 \%, 78 \%$ and $5 \%$ of the patients, respectively.

Dosimetric parameters related to conformity, homogeneity and organ at risk (OAR) sparing are presented in Table 1. All helical tomotherapy plans showed satisfactory conformity index and homogeneity index, being $0.89 \pm 0.13$ and $0.06 \pm 0.07$, respectively. Mean \pm SD of D2\% of spinal cord and brainstem were $34.1 \pm 4.4$ and $53.3 \pm 6.3$ Gy. Mean \pm SD of D50 of contralateral and ipsilateral parotid gland were $28.4 \pm 6.7$ and $38.5 \pm 11.2 \mathrm{~Gy}$. The mean beam on time was 3.91 minutes (range $=3.53-4.21$ minutes).

\section{Discussion}

Several studies have shown the benefits of IMRT, which can reduce dose to the surrounding organs at risk, mainly the parotids, and also allows for dose escalation to the tumour. ${ }^{10-14}$ The use of daily image-guided radiotherapy (IGRT) is necessary in locally advanced nasopharyngeal carcinoma patients in order to reduce marginal miss due to the very steep dose gradients towards the critical structures. $^{15}$

Helical tomotherapy integrates both techniques, IMRT and IGRT, in one machine. Although randomized studies ${ }^{16-20}$ found level 1 evidence of superiority of static beam IMRT over classical 2- and 3-dimensional RT in terms of xerostomia, such evidence is missing for the rotational IMRT techniques, Helical tomotherapy being one of them. 
So clinical evidence is warranted. The study from Leung et al. ${ }^{21}$ demonstrated outstanding 5 year disease control with acceptable toxicity for nasopharyngeal carcinoma treated by helical tomotherapy. Du et al. also reported excellent 3-year LRC, DMFS, and OS with minor acute and late toxicities with helical tomotherapy. ${ }^{22}$ The present data investigated the first 100 nasopharyngeal carcinoma patients treated by helical tomotherapy in Thailand. Our short term 2-year results are excellent with a LRFFS, DMFS, and OS of $94 \%, 96 \%$, and $99 \%$, respectively. This is comparable to the results reported from IGRT studies ${ }^{21-23}$ and other IMRT studies $^{7,21-32}$ as shown in Table 2. Moreover, we have excellent results although more than three thirds $(77 \%)$ of our patients had stage III to IVB disease.

We considered the parotid glands as the most important OARs in regard to quality of life of our patients. We followed RTOG 0225 protocol $^{7}$ in that the mean dose less than or equal to 26 Gy should be achieved in at least 1 gland. This could reduce the degree of xerostomia and therefore we tried to keep the Dmean under 26 Gy whenever possible. Helical tomotherapy offered very good preservation of this organ as also shown by Van Gestel et al. who reported a parotid Dmean with helical tomotherapy of 21.7-24.1 Gy in an oropharyngeal cancer planning study ${ }^{4}$ and of 24.7 Gy as found by Broggi et al. ${ }^{5}$ Specific for nasopharyngeal carcinoma treated by helical tomotherapy, Yao et al..$^{33}$ reported parotid glands Dmean of $30 \mathrm{~Gy}$, whereas Du et al..$^{23}$ used simultaneous modulated accelerated radiation therapy via helical tomotherapy and found that parotid gland Dmean of left and right side were 31.2 Gy and 31.0 Gy, respectively. Finally, Leung et al. reported a very low 22.1 Gy and 20.7 Gy of Dmean of the ipsilateral and contralateral parotid gland, respectively. ${ }^{21}$ Our study had slightly higher D50 of ipsilateral and contralateral parotid glands than the previous studies with 38.5 Gy and 28.4 Gy, respectively. This could be explained by the fact that $95 \%$ of patients in our study were node positive, of whom $60 \%$ had $\geq$ N2 disease. Despite the higher mean dose to both parotid glands, 2 year late grade 2 xerostomia only occurred in $5 \%$ of our patients, with no grade 3 or 4 reported. This $5 \%$ is consistent with the studies by Wong et al. ${ }^{24}$, Lee et al. ${ }^{7}$, and Lee et al. ${ }^{28}$ but is lower than the severe late xerostomia reported by Wang et al..$^{30}$ and Kam et al. ${ }^{26}$, as shown in Table 2. In our study, acute radiation related side effects were mainly pharyngoesophagitis and mucositis. Grade 3 acute pharyngoesophagitis was the most common toxicity, higher than in the study of Du et al. ${ }^{23}$ However the patients in their study received concurrent treatment in $87 \%$ with different chemotherapy regimen and some of them received concurrent anti-EGFR therapy, whereas $100 \%$ of our patients received concurrent treatment with chemotherapy. Moreover, we found that our chemotherapy schedule had higher dose intensity compared to their study. However late pharyngoesophagitis was found in only $2 \%$ of our patients, and was only grade 1 . Grade 3 acute mucositis was less severe and of lower incidence than in other studies as shown in Table 2. ${ }^{24,26,29,31,32}$ Grade 3 acute radiation dermatitis was found in $5 \%$ of our patient, these numbers are comparable to those from other series.22,23,29,32 Other OARs such as brainstem and spinal cord, could be treated within the dose constraint limits.

It has been reported that helical tomotherapy provided excellent conformity and homogeneity index in the treatment of nasopharyngeal carcinoma and other head and neck cancers. ${ }^{21-23} \mathrm{We}$ achieved excellent dose coverage of the three PTVs with homogeneity index and conformity index comparable to the other studies.

We conclude that helical tomotherapy achieved good target coverage in nasopharyngeal cancer patients with favorable dose profile to most of OARs. As such helical tomotherapy achieved favorable 2-year locoregional failure free survival, distant metastasis free survival, and overall survival, with an acceptable rate of moderate and severe acute toxicities, but minimal rate of late toxicities.

\section{Authors' contributions}

IC conceived and coordinated the study, analysed the data, and drafted the manuscript. SC, WN, SJ coordinated and analysed the study. ET, PK, WO, BS, PK, AC participated in acquisition of data. PT, PS performed the statistical analysis. DVG helped to draft the manuscript. All authors read and approved the final manuscript.

\section{References}

1. Kodaira T, Tomita N, Tachibana H, Nakamura T, Nakahara R, Inokuchi H, et al. Aichi cancer center initial experience of intensity modulated radiation therapy for nasopharyngeal cancer using helical tomotherapy. Int J Radiat Oncol Biol Phys 2009; 73: 1129-34. doi:10.1016/j.jijrobp.2008.06.1936

2. Chen AM, Jennelle RLS, Sreeraman R, Yang CC, Liu T, Vijayakumar S, et al. Initial clinical experience with helical tomotherapy for head and neck cancer. Head Neck 2009; 31: 1571-8. doi:10.1002/hed.21123

3. Ren G, Du L, Ma L, Feng L-C, Zhou G-X, Qu B-L, et al. Clinical observation of 73 nasopharyngeal carcinoma patients treated by helical tomotherapy: the China experience. Technol Cancer Res Treat 2011; 10: 259-66. doi:10.7785/ tcrt.2012.500201 
4. Van Gestel D, van Vliet-Vroegindeweij C, Van den Heuvel F, Crijns W, Coelmont A, De Ost B, et al. RapidArc, SmartArc and TomoHD compared with classical step and shoot and sliding window intensity modulated radiotherapy in an oropharyngeal cancer treatment plan comparison. Radiat Oncol 2013; 8: 37. doi:10.1186/1748-717X-8-37

5. Broggi S, Perna L, Bonsignore F, Rinaldin G, Fiorino C, Chiara A, et al. Static and rotational intensity modulated techniques for head-neck cancer radiotherapy: a planning comparison. Phys Med 2014; 30: 973-9. doi:10.1016/j. ejmp.2014.07.001

6. AJCC cancer staging manual. $7^{\text {th }}$ edition. Philadelphia: Lippincott-Raven; 2009.

7. Lee N, Harris J, Garden AS, Straube W, Glisson B, Xia P, et al. Intensitymodulated radiation therapy with or without chemotherapy for nasopharyngeal carcinoma: radiation therapy oncology group phase II trial 0225 . J Clin Oncol 2009; 27: 3684-90. doi:10.1200/JCO.2008.19.9109

8. US National Institute of Health. Cancer Therapy Evaluation Program. Common terminology criteria for adverse events v3.0 (CTCAE). [citated 2017 Aug 9]. Available at https://ctep.cancer.gov/protocoldevelopment/ electronic_applications/docs/ctcaev3.pdf

9. Cox JD, Stetz J, Pajak TF. Toxicity criteria of the Radiation Therapy Oncology Group (RTOG) and the European Organization for Research and Treatment of Cancer (EORTC). Int J Radiat Oncol Biol Phys 1995; 31: 1341-6. doi:10.1016/0360-3016(95)00060-C

10. Nutting C, Dearnaley DP, Webb S. Intensity modulated radiation therapy: a clinical review. Br J Radiol 2000; 73: 459-69.

11. Eisbruch A, Ship JA, Martel MK, Ten Haken RK, Marsh LH, Wolf GT, et al. Parotid gland sparing in patients undergoing bilateral head and neck irradiation: techniques and early results. Int J Radiat Oncol Biol Phys 1996; 36: 469-80. doi:10.1259/bjr.73.869.10884741

12. Eisbruch A, Ten Haken RK, Kim HM, Marsh LH, Ship JA. Dose, volume, and function relationships in parotid salivary glands following conformal and intensity-modulated irradiation of head and neck cancer. Int J Radiat Oncol Biol Phys 1999; 45: 577-87.

13. Kreps S, Berges O, Belin L, Zefkili S, Petras S, Giraud P. Salivary gland-sparing helical tomotherapy for head and neck cancer: Preserved salivary function on quantitative salivary gland scintigraphy after tomotherapy. Eur Ann Otorhinolaryngol Head Neck Dis 2016; 133: 257-62. doi:10.1016/j. anorl.2016.05.003

14. Voordeckers M, Farrag A, Everaert H, Tournel K, Storme G, Verellen D, et al. Parotid gland sparing with helical tomotherapy in head-and-neck cancer. Int J Radiat Oncol Biol Phys 2012; 84: 443-8. doi:10.1016/j.jijrobp.2011.11.070

15. Jiang $F$, Jin $T$, Feng $X-L$, Jin $Q-F$, Chen $X-Z$. Long-term outcomes and failure patterns of patients with nasopharyngeal carcinoma staged by magnetic resonance imaging in intensity-modulated radiotherapy era: The Zhejiang Cancer Hospital's experience. J Cancer Res Ther 2015; 11(Suppl 2): C179-84 doi:10.4103/0973-1482.168181

16. Pow EH, Kwong DL, McMillan AS et al. Xerostomia and quality of life afte intensity-modulated radiotherapy versus conventional radiotherapy for early-stage nasopharyngeal carcinoma: initial report on a randomized controlled clinical trial. Int J Radiat Oncol Biol Phys 2006; 66: 981-91.

17. Kam MK, Leung SF, Zee B, Chau RM, Suen JJ, Mo F et al. Prospective randomized study of intensity-modulated radiotherapy on salivary gland function in early-stage nasopharyngeal carcinoma patients. J Clin Oncol. 2007; 25(31): 4873-9.

18. Nutting C, Morden J, Harrington K, Urbano TG, Bhide SA, Clark C et al. Parotid-sparing intensity modulated versus conventional radiotherapy in head and neck cancer (PARSPORT): a phase 3 multicentre randomised controlled trial. Lancet Oncol 2011; 12: 127-36.

19. Gupta T, Agarwal J, Jain $\mathrm{S}$ et al. Three-dimensional conformal radiotherapy (3D-CRT) versus intensity modulated radiation therapy (IMRT) in squamous cell carcinoma of the head and neck: A randomized controlled trial. Radiother Oncol. 2012; 104: 343-48.

20. Peng $G$, Wang T, Yang KY et al. A prospective, randomized study comparing outcomes and toxicities of intensity-modulated radiotherapy vs. conventional two-dimensional radiotherapy for the treatment of nasopharyngeal carcinoma. Radiother Oncol. 2012; 104: 286-93.

21. Leung SW, Lee T-F. Treatment of nasopharyngeal carcinoma by tomotherapy: five-year experience. Radiat Oncol 2013; 8: 107. doi:10.1186/1748717X-8-107
22. Du L, Zhang X-X, Ma L, Feng L-C, Li F, Zhou G-X, et al. Clinical study of nasopharyngeal carcinoma treated by helical tomotherapy in China: 5-year outcomes. Biomed Res Int 2014; e980767. doi:10.1155/2014/980767

23. Du L, Zhang XX, Feng LC, Chen J, Yang J, Liu HX, et al. Treatment of nasopharyngeal carcinoma using simultaneous modulated accelerated radiation therapy via helical tomotherapy: a phase II study. Radiol Oncol 2016; 50: 218-25. doi:10.1515/raon-2016-0001

24. Wong FCS, Ng AWY, Lee VHF, Lui CMM, Yuen K-K, Sze W-K, et al. Wholefield simultaneous integrated-boost intensity-modulated radiotherapy for patients with nasopharyngeal carcinoma. Int J Radiat Oncol Biol Phys 2010; 76: 138-45. doi:10.1016/j.jijrobp.2009.01.084

25. Wolden SL, Chen WC, Pfister DG, Kraus DH, Berry SL, Zelefsky MJ. Intensitymodulated radiation therapy (IMRT) for nasopharynx cancer: update of the Memorial Sloan-Kettering experience. Int J Radiat Oncol Biol Phys 2006; 64 57-62. doi:10.1016/j.jijobp.2005.03.057

26. Kam MKM, Teo PML, Chau RMC, Cheung KY, Choi PHK, Kwan WH, et al. Treatment of nasopharyngeal carcinoma with intensity-modulated radiotherapy: the Hong Kong experience. Int J Radiat Oncol Biol Phys 2004; 60: 1440-50. doi:10.1016/j.ijrobp.2004.05.022

27. Tham IW-K, Hee SW, Yeo RM-C, Salleh PB, Lee J, Tan TW-K, et al. Treatment of nasopharyngeal carcinoma using intensity-modulated radiotherapy-the national cancer centre singapore experience. Int J Radiat Oncol Biol Phys 2009; 75: 1481-6. doi:10.1016/j.ijrobp.2009.01.018

28. Lee N, Xia P, Quivey JM, Sultanem K, Poon I, Akazawa C, et al. Intensitymodulated radiotherapy in the treatment of nasopharyngeal carcinoma: an update of the UCSF experience. Int J Radiat Oncol Biol Phys 2002; 53: 12-22.

29. Liu W-S, Su M-C, Wu M-F, Tseng H-C, Kuo H-C. Nasopharyngeal carcinoma treated with precision-oriented radiation therapy techniques including intensity-modulated radiotherapy: preliminary results. Kaohsiung J Med Sci 2004; 20: 49-55. doi:10.1016/S1607-551X(09)70084-1

30. Wang R, Wu F, Lu H, Wei B, Feng G, Li G, et al. Definitive intensity-modulated radiation therapy for nasopharyngeal carcinoma: long-term outcome of a multicenter prospective study. J Cancer Res Clin Oncol 2013; 139: 139-45. doi:10.1007/s00432-012-1313-0

31. Sultanem K, Shu HK, Xia P, Akazawa C, Quivey JM, Verhey L, et al. Threedimensional intensity-modulated radiotherapy in the treatment of nasopharyngeal carcinoma: the University of California-San Francisco experience. Int J Radiat Oncol Biol Phys 2000; 48: 711-22.

32. Zhang X, Du L, Zhao F, Wang Q, Yang S, Ma L. A Phase II clinical trial of concurrent helical tomotherapy plus cetuximab followed by adjuvant chemotherapy with cisplatin and docetaxel for locally advanced nasopharyngeal carcinoma. Int J Biol Sci 2016; 12: 446-53. doi:10.7150/ijbs.12937

33. Yao W, Du L, Ma L, Feng L, Cai B, Xu S, et al. Effect of adaptive replanning on adverse reactions and clinical outcome in nasopharyngeal carcinoma treated by helical tomotherapy. Zhong Nan Da Xue Xue Bao Yi Xue Ban 2013; 38: 468-75. doi:10.3969/j.issn.1672-7347.2013.05.005 